\title{
Acute Intermittent Porphyria With Seizure and Paralysis in the Puerperium
}

\section{Yi-Kong Keung, MD, Temduang Chuabirun, MD, and Everardo Cobos, MD}

Porphyrias are a group of metabolic disorders, usually genetic in origin, secondary to deficiencies of various enzymes involved in the heme biosynthetic pathways. They are usually classified into hepatic and erythropoietic types based on the major sites of the porphyrin production. It is more clinically useful, however, to classify this disorder into acute and nonacute types based on the clinical findings. Acute type includes the acute intermittent porphyria, variegate porphyria, and hereditary coproporphyria. The nonacute type includes the porphyria cutanea tarda and erythropoietic porphyrias.

Acute intermittent porphyria is the most severe form of the disease, with gastrointestinal and neuropsychiatric manifestations, such as abdominal pain, vomiting, peripheral neuropathy (motor, sensory, and autonomic), hypertension, seizures, depression, psychosis, and so on. Pregnancy complicating a known diagnosis of porphyria has been reported as early as in the 1950 s. A first attack of acute porphyria with pregnancy is rare, however. ${ }^{1-11}$ This disease can be a diagnostic challenge to obstetricians and family physicians. It is important that physicians are alert to porphyria so they can make this diagnosis promptly, because proper management will dramatically improve the outcome in this otherwise debilitating and potentially life-threatening disease.

We describe a very rare case of acute intermittent porphyria in which the patient had a generalized seizure and progressive paralysis in the puerperium.

\section{Case Report}

A 20-year old woman, gravida 2, para 2, had a generalized seizure and hypertension 3 days after

Submitted, revised, 25 November 1998.

From the Division of Hematology/Oncology (YK, EC), Department of Internal Medicine (TC), Texas Tech University Health Sciences Center, Lubbock. Address reprint requests to Yi-Kong Keung, MD, Wake Forest University Comprehensive Cancer Center, Medical Center Blvd, Winston-Salem, NC 27157. an emergency cesarean delivery of her second child at 33 weeks' gestation complicated by pyelonephritis. She was given ciprofloxacin, phenytoin, and nifedipine. A computerized tomographic scan of the brain was normal. Magnetic resonance imaging of the brain showed two small, nonspecific demyelinating areas in the left posterior parietal region at the level of the lateral ventricle. There was no evidence of cerebral tumor, hemorrhage, or infarct. She was transferred to our hospital for management of her poorly controlled generalized seizure. At admission, the patient was lethargic, which was attributed to a phenytoin overdose of $33.9 \mu \mathrm{g} / \mathrm{mL}$ (therapeutic level 10 to $20 \mu \mathrm{g} / \mathrm{mL}$ ). Her serum sodium was $119 \mathrm{mEq} / \mathrm{L}$, potassium $3.1 \mathrm{mEq} / \mathrm{L}$, chloride $79 \mathrm{mEq} / \mathrm{L}$, bicarbonate $31 \mathrm{mEq} / \mathrm{L}$, blood urea nitrogen $10 \mathrm{mg} / \mathrm{dL}$, and creatinine $0.6 \mathrm{mg} / \mathrm{dL}$. Alanine transaminase was $64 \mathrm{U} / \mathrm{L}$, aspartate transaminase was $78 \mathrm{U} / \mathrm{L}$, and alkaline phosphatase was 239 U/L. Study results of the serum and urine osmolarity were consistent with the syndrome of inappropriate antidiuretic hormone (SIADH).

Despite having her electrolyte abnormalities and phenytoin level corrected in the next few days, the patient remained lethargic, and her upper and lower limbs became progressively weaker. Her tendon reflexes were markedly decreased, but her plantar reflex was normal. Initially a consulting neurologist suggested a probable diagnosis of postpartum Guillain-Barré syndrome. Intravenous immunoglobulin and plasma exchange was started with no response. A subsequent nerve conduction study showed mildly prolonged latencies and reduced amplitude of the peroneal nerve. Conduction velocity was within normal limits.

Other causes of muscle weakness with hyporeflexia and preserved plantar reflex were sought. Analysis of her cerebrospinal fluid showed no white blood cells, her protein level was $63 \mathrm{mg} / \mathrm{dL}$ and glucose $56 \mathrm{mg} / \mathrm{dL}$, and she had a nonreactive VDRL test. Her aldolase level was within normal limits; hence, myopathy was unlikely. Heavy-metal poisoning was considered as a cause of peripheral 


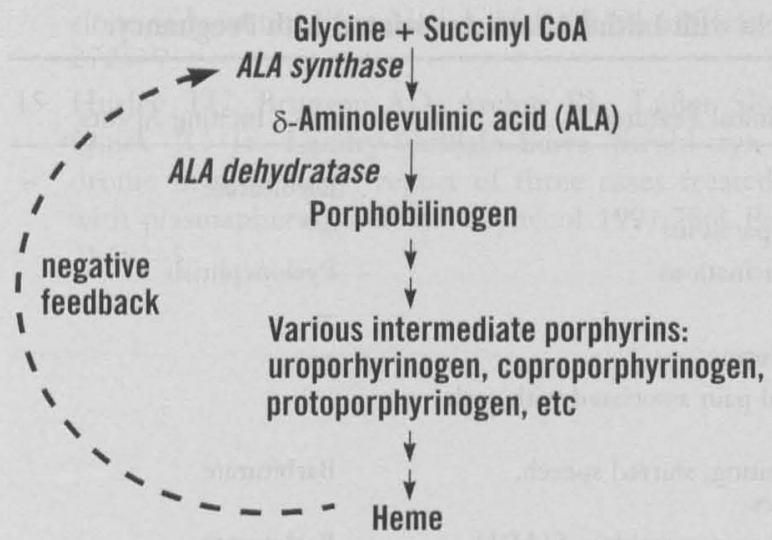

Figure 1. Biosynthetic pathway of heme.

neuropathy, but her blood mercury and lead levels were normal. Antinuclear antibody level was borderline at a low titer of 1:80. Lyme disease was unlikely after a negative test for Borrelia burgdorferi antibodies (enzyme-linked immunosorbent assay). Urine screening for porphobilinogen by the Watson-Schwartz test was positive. Subsequently 24-hour urine quantitation of porphobilinogen was $139.5 \mathrm{mg} / 24 \mathrm{~h}$ (normal $\leq 2.7 \mathrm{mg} / 24 \mathrm{~h}$ ), $\delta$-aminolevulinic acid $39 \mathrm{mg} / 24 \mathrm{~h}$ (normal $\leq 6.4 \mathrm{mg} / 24 \mathrm{~h}$ ), uroporphyrin $1279.7 \mu \mathrm{g} / 24 \mathrm{~h}$ (normal 3.3-29.5 $\mu \mathrm{g} / 24 \mathrm{~h}$ ), and coproporphyrin $637.9 \mu \mathrm{g} / 24 \mathrm{~h}$ (nor$\mathrm{mal} \leq 155 \mu \mathrm{g} / 24 \mathrm{~h}$ ). Acute porphyria was confirmed. The patient was given a high-carbohydrate diet, and hematin, $4 \mathrm{mg} / \mathrm{kg}$ (Abbott Laboratories, Chicago), was given intravenously daily for 2 weeks. Her recovery of motor function was slow but definite. Although 1 year later she continues to have wrist and foot drop, she is ambulatory with ankle braces and is able to attend to her normal daily activities with wrist support.

\section{Discussion}

The many precipitating factors that are known to induce acute porphyria attacks in susceptible persons include hormonal changes associated with pregnancy and menstrual cycle, reduced caloric intake, drugs, stress, and infections. Barbiturates, sulfonamide, anticonvulsants, and oral contraceptives are by far the most common drugs implicated in acute porphyria. These conditions or medications directly or indirectly induce the $\delta$-aminolevulinic acid synthase activity, which results in an increased biosynthesis of heme and the various intermediate porphyrins (Figure 1).
Pregnancy and its associated hormonal changes increase porphyrin metabolism and therefore can precipitate acute porphyria attacks. Nevertheless, our patient had an uneventful first pregnancy, and only after delivery of her second child was porphyria diagnosed. In Table $1^{1-11}$ we summarize all reported cases of acute porphyria in which the initial attack was associated with pregnancies. In 10 of 14 cases the women had normal or apparently normal pregnancies before the initial diagnosis. Alternatively, the symptoms might have been so mild and nonspecific that the diagnosis was missed in previous pregnancies, as in case 6 . In eight cases the patients were exposed to a known inciting agent or infection. This finding probably suggests that pregnancy alone might be insufficient to induce an attack. According to the study of pregnancy outcome in patients with known porphyria, the attack rate is only $16 \%$ in the antenatal period and $8 \%$ in puerperium. $^{12}$

We believe that the initial porphyria attack, which took the form of a generalized seizure and hypertension in our patient, occurred after cesarean delivery and probably was related to reduced caloric intake after surgery and pyelonephritis. The use of phenytoin and nifedipine to control her seizure and hypertension further aggravated the metabolic derangement, resulting in progressive motor neuropathy. In our patient severe hyponatremia and SIADH at diagnosis were probably due to the hypothalamic involvement of acute porphyria and the salt-losing state of pyelonephritis. ${ }^{6,13}$ The treatment of acute porphyria is high-caloric intake and hematin. ${ }^{13,14}$ The precise mechanism of high-caloric diet to abrogate acute porphyria attack is unclear. Increased glucose intake in animals has been shown, however, to repress the inducing effect of chemicals on $\delta$-aminolevulinic acid synthase. Hematin, a derivative from processed red blood cells, is believed to inhibit $\delta$-aminolevulinic acid synthase activity directly and hence decrease the production and accumulation of various porphyrins (Figure 1).

Another important differential diagnosis of progressive weakness associated with pregnancy is Guillain-Barré syndrome. ${ }^{15-17} \mathrm{~A}$ recent retrospective study of Guillain-Barré syndrome associated with pregnancy revealed that the risk tends to increase in the puerperium. ${ }^{17}$ The similar presenting features of both Guillain-Barré syndrome and acute porphyria and the equivocal findings of the nerve 


\begin{tabular}{|c|c|c|c|c|}
\hline Case & $\begin{array}{l}\text { Age }(y) \\
\text { Gravida, Para }\end{array}$ & $\begin{array}{l}\text { Gestational Age } \\
\text { at Diagnosis }\end{array}$ & Clinical Features & Inciting Agents \\
\hline $1^{1}$ & 25, G1P0 & 12 weeks & Seizure, coma & Barbiturate \\
\hline $2^{1}$ & 26, G1P0 & 8 weeks & Vomiting, lethargy, paralysis & $一^{*}$ \\
\hline $3^{t}$ & $38, \mathrm{G} 2 \mathrm{P} 2$ & Puerperium & Paranoid ideas, hallucinations & Pyelonephritis \\
\hline $4^{2}$ & 27, G3P2 & 1st trimester & Abdominal pain & - \\
\hline $5^{3}$ & 22, G12P11 & 1st trimester & Epigastric pain, red urine & - \\
\hline $6^{4}$ & 22, G4P3 & 10 weeks & $\begin{array}{l}\text { Recurrent abdominal pain associated with each } \\
\text { pregnancy }\end{array}$ & - \\
\hline $7^{5}$ & 23, G1P1 & Puerperium & $\begin{array}{l}\text { Epigastric pain, vomiting, slurred speech, } \\
\text { personality changes }\end{array}$ & Barbiturate \\
\hline $8^{6}$ & $16, \mathrm{G} 1 \mathrm{P} 0$ & 32 weeks & Anemia, retrosternal pain, vomiting, SIADH & Barbiturate \\
\hline $9^{7}$ & 21, G1P0 & 29 weeks & Abdominal pain, vomiting, motor neuropathy & Sulfa drug \\
\hline $10^{8}$ & 27, G2P1 & 10 weeks & $\begin{array}{l}\text { Abdominal pain, mental changes, irritability, } \\
\text { depression, motor neuropathy }\end{array}$ & Metoclopramide \\
\hline $11^{9}$ & 29, G2P1 & 1st trimester & Positive screening with family history & - \\
\hline $12^{10}$ & $23, \mathrm{G} 2 \mathrm{P} 1$ & 36 weeks & Mental changes, ataxia & - \\
\hline $13^{11}$ & $29, \mathrm{G} 3 \mathrm{P} 2$ & 13 weeks & $\begin{array}{l}\text { Abdominal pain, vomiting, depression, } \\
\text { hallucination, memory loss, irritability }\end{array}$ & Metoclopramide \\
\hline Current & $20, \mathrm{G} 2 \mathrm{P} 2$ & Puerperium & Seizure, SIADH, and progressive quadriplegia & $\begin{array}{l}\text { Pyelonephritis, phenytoin, } \\
\text { and nifedipine }\end{array}$ \\
\hline
\end{tabular}

SIADH - syndrome of inappropriate antidiuretic hormone.

*None or not stated.

conduction study have contributed to the initial misdiagnosis in our case. In retrospect, our patient's mental symptoms, SIADH, and normal nerve conduction velocity probably speaks more for the diagnosis of acute porphyria.

Finally, we cannot emphasize more that a high index of suspicion is important to make the correct diagnosis of acute porphyria, because proper management will dramatically improve the outcome in this debilitating and potentially life-threatening disease.

\section{References}

1. Neilson DR, Neilson RP. Porphyria complicated by pregnancy. West J Surg 1958;66:134-49.

2. Salokannel J, Rhen K. Acute intermittent porphyria and pregnancy. Acta Obstet Gynecol Scand 1969;48: 1-7.

3. Shapiro HI, Mazur JR, Emich JP Jr. Acute intermittent porphyria and pregnancy. Obstet Gynecol 1969; 34:189-93.

4. Nomanbhoy YT, Katz A. Porphyria and pregnancy. Chic Med Sch Q 1969;28:26-8.

5. Hunter DJ. Acute intermittent porphyria and pregnancy. J Obstet Gynaecol Br Commonw 1971;78: $746-50$.

6. Kerr GD. Acute intermittent porphyria and inappro- priate secretion of antidiuretic hormone in pregnancy. Proc R Soc Med 1973;66:763-4.

7. Lenehan PM, Turner MJ, Boylan P, MacDonald D. Acute intermittent porphyria in pregnancy-a case report. Ir J Med Sci 1982;151:155-7.

8. Milo R, Neuman M, Klein C, Caspi E, Arlazoroff A. Acute intermittent porphyria in pregnancy. Obstet Gynecol 1989;73(3 Pt 2):450-2.

9. Kantor G, Rolbin SH. Acute intermittent porphyria and caesarean delivery. Can J Anaesth 1992; $39: 282-5$.

10. Soriano D, Seidman DS, Mashiach S, Sela BA, Blonder J. Acute intermittent porphyria first diagnosed in the third trimester of pregnancy. Case report. J Perinat Med 1996;24:185-9.

11. Shenhav S, Gemer O, Sassoon E, Segal S. Acute intermittent porphyria precipitated by hyperemesis and metoclopramide treatment in pregnancy. Acta Obstet Gynecol Scand 1997;76:484-5.

12. Brodie MJ, Moore MR, Thompson GG, Goldberg A, Low RA. Pregnancy and the acute porphyrias. Br J Obstet Gynaecol 1977;84:726-31.

13. Tschudy DP, Valsamis M, Magnussen CR. Acute intermittent porphyria: clinical and selected research aspects. Ann Intern Med 1975;83:851-64.

14. Bonkowsky HL, Tschudy DP, Collins A, et al. Repression of overproduction of porphyrin precursors in acute intermittent porphyria by intravenous infu- 
sions of hematin. Proc Natl Acad Sci USA 1971;68: 2725-9.

15. Hurley TU, Brunson AD, Archer RL, Lefler SF, Quirk JG Jr. Landry-Guillain-Barré Strohl syndrome in pregnancy: report of three cases treated with plasmapheresis. Obstet Gynecol 1991;78(3 Pt 2):482-5.
16. Kuller JA, Katz VL, McCoy MC, Hansen WF. Pregnancy complicated by Guillain-Barré syndrome. South Med J 1995;88:987-9.

17. Jiang GX, de Pedro-Cuesta J, Strigard K, Olsson T, Link H. Pregnancy and Guillain-Barré syndrome: a nationwide register cohort study. Neuroepidemiology 1996;15:192-200. 